\title{
Diagnóstico de las infecciones asociadas a catéteres vasculares centrales
}

\author{
PATRICIA GARCÍA C. ${ }^{1}$, ERNESTO PAYÁ G. ${ }^{1}$, ROBERTO OLIVARES C. ${ }^{1}$, \\ ALEJANDRO COTERA F. ${ }^{2}$, JAIME RODRÍGUEZ T. ${ }^{1}$ y MARCELA SANZ R. ${ }^{3}$
}

Diagnosis of catheter related infection

\section{Introducción}

Los catéteres intravasculares son dispositivos plásticos que permiten acceder al compartimiento intravascular a nivel central. Varían en su diseño y estructura según se utilicen en forma temporal (días) o permanente (semanas, meses) así como también en el material con que son fabricados, en el número de lúmenes, y en el motivo por el cual se instalan.

El uso de estos dispositivos ha sido de gran utilidad clínica ya que permiten un acceso rápido y seguro al torrente sanguíneo, pudiendo ser utilizados para la administración de fluidos endovenosos, medicamentos, productos sanguíneos, nutrición parenteral total, monitoreo del estado hemodinámico y para hemodiálisis. Sin embargo, no están exentos de riesgos habiéndose descrito complicaciones mecánicas e infecciosas.

La infección relacionada a catéteres centrales constituye una de las principales complicaciones de su uso y la primera causa de bacteriemia nosocomial primaria. La incidencia de bacteriemia atribuible a su uso es variable entre distintos centros hospitalarios. Dada la importancia de estas infecciones, tanto en morbimortalidad como en los costos asociados, resulta fundamental contar con un consenso para el diagnóstico de la infección relacionada a dispositivos vasculares, que permita tomar conductas adecuadas tanto para su prevención como en el tratamiento.

\section{Propósito}

El propósito de este primer documento-con- senso es contribuir al mejor manejo de los dispositivos de acceso vascular central, mediante recomendaciones basadas en evidencia, para el diagnóstico de las complicaciones infecciosas que se presentan en el uso de estos.

\section{Clasificación de los dispositivos vasculares centrales}

- Según la localización los catéteres vasculares pueden ser periféricos o centrales.

- Según el tiempo de permanencia pueden ser temporales, transitorios o de corta duración; o permanentes o de larga duración (Figura 1).

- Según el material de fabricación pueden ser de silicona, teflón, recubiertos o impregnados.

Catéter venoso central común (CVC): Es el dispositivo intravascular más ampliamente usado. Se inserta en forma percutánea, a través de un acceso venoso central (vena subclavia, yugular o femoral). Los CVCs son frecuentemente utilizados en unidades de cuidados intensivos con variados objetivos: infusión de fármacos, monitoreo hemodinámico, plasmaféresis, nutrición parenteral total, etc. Las tasas de infección asociadas al uso de este tipo de dispositivos han ido en aumento en las últimas décadas, debido probablemente a su mayor uso y a la mayor complejidad de los pacientes en quienes se utilizan. Por tratarse de un dispositivo concebido para emplear por corto tiempo y no ser implantado quirúrgicamente, la metodología diagnóstica puede evaluarse considerando la disyuntiva de remover o no el catéter.

Catéter central periféricamente instalado CCPI (Peripherically instaled central catheter-

\footnotetext{
Sociedad Chilena de Infectología.

Sociedad Chilena de Nefrología

Unidad de Recién Nacido. Hospital Luis Calvo Mackenna.
}

Recibido: 8 enero 2003

Aceptado: 4 marzo 2003 


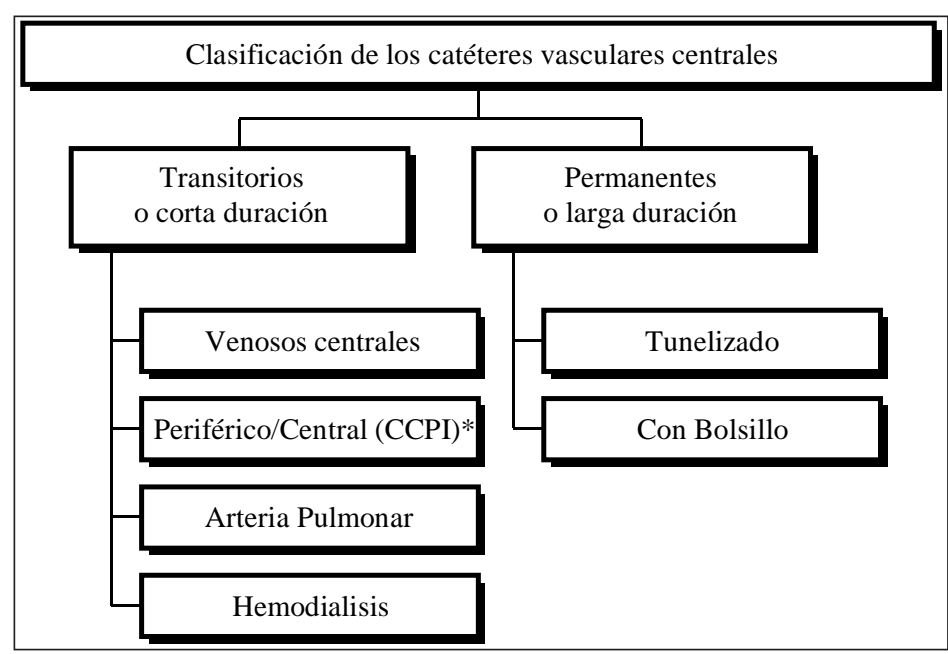

Figura 1. Clasificación de los catéteres vasculares centrales según tiempo de permanencia. *Catéter venoso central periféricamente instalado.

Catéter tunelizado: Es el dispositivo más utilizado cuando se necesita un acceso prolongado a la circulación central, ya sea para la administración de quimioterapia o apoyo nutricional parenteral de larga duración. Los de tipo Hickman-Broviac poseen un cuff o manguito y un trayecto subcutáneo que impide su desplazamiento, y su extremo proximal queda externalizado; en cambio, los de tipo Port poseen un reservorio ubicado en un bolsillo subcutáneo y quedan totalmente implantados. Ambos tipos poseen ventajas y desventajas, de modo que la elección de uno u otro debe decidirse en cada paciente atendiendo a fac-

PICC): Es un dispositivo de silicona biocompatible y radiopaco, cuya inserción es periférica, pero la ubicación de su extremo distal ("punta") es central (vena cava superior o subclavia). Posee un introductor de teflón divisible o scalp vein. Se ha utilizado ampliamente en neonatología, ya que permite un acceso central rápido y seguro por vía periférica, la administración de todo tipo de soluciones, mayor comodidad y confort al paciente y registra una baja incidencia de complicaciones. Se han desarrollado también CCPI para larga duración.

Catéter de hemodiálisis: Para este caso la infección del sitio de inserción y la infección del túnel tienen las mismas definiciones que las de los otros catéteres (ver más adelante). En la infección del torrente sanguíneo se debe tener en consideración que el cuadro febril, con calofríos y eventual compromiso hemodinámico, si bien puede presentarse en cualquier momento del período interdiálisis, muchas veces ocurre durante la diálisis.

No existe consenso en este tipo de catéteres sobre cuál es el lugar más adecuado para la toma de los hemocultivos. Los hemocultivos obtenidos mediante venopunción o periféricos han sido señalados como el gold standard para el diagnóstico de septicemia. En hemodiálisis el circuito extracorpóreo es una extensión del aparato circulatorio y por lo tanto, los hemocultivos tomados desde el circuito han sido valorados como equivalentes a los tomados desde una vena periférica. Los cultivos tomados directamente desde las ramas del catéter tienen una mayor posibilidad de ser falsamente positivos dado que el $68 \%$ de los catéteres se colonizan sin necesariamente producir bacteriemia ${ }^{1}$. tores tales como edad, condiciones sociales, frecuencia de controles, disponibilidad quirúrgica, etc. Los de tipo port tienen una menor tasa de infecciones -pero cuando se infecta el reservorio, las complicaciones son más graves- y una mayor tasa de complicaciones de tipo mecánico.

\section{Patogenia de la infección del dispositivo}

La piel y la conexión son las principales fuentes de la colonización del catéter. La adherencia y colonización de los microorganismos al catéter con formación de una matriz biológica representa uno de los eventos iniciales que conducen posteriormente a la septicemia relacionada al catéter. En 1995, Raad et al demostraron en un análisis microbiológico y ultraestructural, que ambas vías de colonización ocurren y que la preponderancia de una u otra depende del tiempo de permanencia del $\mathrm{CVC}^{2}$. En catéteres de corta duración la colonización es fundamentalmente de la superficie externa, por microorganismos de la piel del sitio de inserción ${ }^{3}$; en cambio, en los de larga duración predomina la colonización de la superficie interna ${ }^{4}$. Los microorganismos colonizarían la conexión a través de las manos contaminadas del personal que manipula la conexión.

Estos fenómenos deben tenerse en cuenta para elegir los métodos de diagnósticos más adecuados.

\section{Definiciones}

Es necesario definir las categorías de los diferentes fenómenos infecciosos 5 .

Colonización del catéter: Crecimiento significativo de un microorganismo en un cultivo cuantitativo o semicuantitativo del extremo distal 
del dispositivo, del segmento subcutáneo o de la conexión. Este fenómeno no implica bacteriemia ni requiere de tratamiento antimicrobiano.

Flebitis: Induración o eritema con aumento de la temperatura local y/o dolor alrededor del sitio de inserción del catéter.

Infección del sitio de inserción: Eritema, induración, mayor sensibilidad y/o exudado en un área de $2 \mathrm{cms}$ en torno al punto de exteriorización, con o sin aislamiento de un microorganismo. Puede asociarse o no con otros síntomas y signos de infección tales como fiebre o pus en el sitio de salida, con o sin infección del torrente sanguíneo concomitante. En el caso de catéteres de hemodiálisis algunos autores consideran entre éstas a las infecciones que comprometen el trayecto subcutáneo del catéter por fuera del cuff.

Infección del túnel: Eritema, aumento de la sensibilidad y/o induración a más de $2 \mathrm{~cm}$ del sitio de salida, a lo largo del trayecto subcutáneo (por dentro del cuff) de un catéter tunelizado (Hickman, Broviac o de hemodiálisis), con o sin infección concomitante del torrente sanguíneo.

Infección del bolsillo: Infección con salida de fluido en el bolsillo subcutáneo de un catéter totalmente implantable. A veces asociado con aumento de la sensibilidad, eritema y/o induración sobre el bolsillo. Puede haber rotura espontánea y drenaje o necrosis de la piel que cubre el reservorio, con o sin infección del torrente sanguíneo concomitante.

Infección del torrente sanguíneo. Relacionada a la infusión: Crecimiento del mismo microorganismo desde la infusión y desde hemocultivos periféricos, sin evidencia de otra fuente de infección. Relacionada al catéter: Bacteriemia o fungemia en un paciente con un dispositivo vascular con uno o más hemocultivos periféricos positivos, con manifestaciones clínicas de infección (fiebre, calofríos y/o hipotensión) y sin otra fuente aparente de infección del torrente sanguíneo. Además se deben cumplir al menos una de las siguientes condiciones:

- Cultivo positivo del extremo del catéter $(\geq 15$ ufc en su extremo distal por el método semicuantitativo o $\geq 100$ ufc del cultivo cuantitativo) con identificación del mismo microorganismo que en la sangre (igual especie y antibiograma).

- Hemocultivos cuantitativos simultáneos a través del catéter y por venopunción con una razón $\geq 4: 1$ (sangre por catéter $v s$ sangre periférica).

- Tiempo diferencial hasta detectarse crecimiento bacteriano, de al menos 2 horas entre el hemocultivo obtenido por catéter y el hemocultivo periférico, lapso medible sólo en labo- ratorios que disponen de sistemas automatizados de hemocultivos.

En algunas ocasiones los estudios microbiológicos son negativos (cultivo del extremo distal del dispositivo y hemocultivos), observándose sin embargo, mejoría del cuadro clínico una vez que el catéter ha sido retirado.

\section{Métodos de diagnóstico microbiológico}

Independiente del tipo de catéter central, los métodos de diagnóstico se han clasificado en:

- Métodos de diagnóstico no conservadores o que requieren la remoción del catéter.

- Métodos de diagnóstico conservadores o que no requieren la remoción del catéter.

\section{Métodos de diagnóstico no conservadores (con remoción del catéter)}

La principal desventaja de estos métodos es que requieren el retiro del catéter y como se ha estimado que entre 75 y $85 \%$ de los catéteres se retiran innecesariamente durante la evaluación de un cuadro febril ${ }^{6}$, estos métodos representan un alto costo. En general, las indicaciones de remoción del catéter son bacteriemia y/o sepsis persistente por más de 48 a 72 horas, presencia de complicaciones locales evidentes, presencia de complicaciones metastásicas (endocarditis infecciosa, embolia pulmonar o periférica), aislamiento de microorganismos difíciles de erradicar (levaduras, $S$. aureus, Pseudomonas sp), recurrencia de la infección después de discontinuar el tratamiento antimicrobiano o, de acuerdo al criterio del médico clínico que enfrenta un paciente con signos y síntomas de sepsis severa sin un foco evidente, en presencia de un CVC. Cada vez que se tome la decisión de retirar un catéter con la sospecha clínica de que existe una infección sistémica asociada a este dispositivo, es necesario obtener hemocultivos por venopunción y enviar un segmento del catéter que incluya su extremo distal a estudio microbiológico aplicando las técnicas que a continuación se describen.

Se han desarrollado cultivos cualitativos, cuantitativos, semicuantitativos y tinciones del catéter:

Cultivo cualitativo. Consiste en la introducción del extremo distal del catéter en un caldo de cultivo. Su sensibilidad para detectar colonización del catéter es cercana a $100 \%$. Sin embargo, basta la presencia de un microorganismo para que el cultivo sea positivo, por lo cual su especificidad para colonización es menor de $50 \%$.

Cultivo cuantitativo.

- Método de flush, barrido o irrigación: descrito 
por Cleri et $\mathrm{al}^{8}$, consiste en un barrido del lumen con $2 \mathrm{ml}$ de caldo (flush), del cual se hacen diluciones seriadas y siembra posterior en placa. Se considera positivo el cultivo si existe un desarrollo microbiano mayor o igual a $1.000 \mathrm{ufc} / \mathrm{ml}$. Con este punto de corte, los autores encontraron $100 \%$ de sensibilidad y $92 \%$ de especificidad en el diagnóstico de bacteriemia relacionada a CVC. Liñares et $\mathrm{al}^{4}$ demostraron por este método, que $70 \%$ de las septicemias relacionadas a CVC presentaban colonización de la superficie interna en catéteres con permanencia promedio de 23 días. Rello et $\mathrm{al}^{9}$ demostraron una sensibilidad de $53,8 \%$ en el diagnóstico de bacteriemia relacionada a CVC que tenían una permanencia promedio cercana a los 13 días. El método de Cleri implica un procedimiento simple, no requiere equipamiento, pero sólo recupera microorganismos intraluminales.

- Método cuantitativo simplificado: descrito por Brun-Buisson et $\mathrm{al}^{10}$. En una modificación al método de Cleri, se hace pasar $1 \mathrm{ml}$ de agua destilada estéril por el lumen del catéter y luego se somete a vórtex durante 1 minuto. Se siembra $0,1 \mathrm{ml}$ de esta suspensión en una placa de agar sangre de cordero al $5 \%$ y se incuba durante 5 días. Se considera significativo un desarrollo mayor de $1.000 \mathrm{ufc} / \mathrm{ml}$. Para el diagnóstico de bacteriemia asociada a CVC presenta una sensibilidad de $97,5 \%$ y una especificidad de $88 \%$. Recupera microorganismos de la superficie interna y externa del dispositivo.

- Sonicación: descrito por Sherertz et al ${ }^{11}$, consiste en depositar el segmento del catéter en un tubo con $10 \mathrm{ml}$ de caldo tripticasa de soya y se somete a sonicación a 55.000 hertz durante un minuto. Se toman muestras del caldo $(100 \mu \mathrm{l})$ y se le agregan 0,9 y $9,9 \mathrm{ml}$ respectivamente (para obtener diluciones de 1: 10 y 1: 100). Se siembran $100 \mu 1$ de cada dilución en una placa de agar sangre de cordero y se incuba hasta 48 horas. Se considera significativo un recuento $\geq 10^{3} \mathrm{ufc} / \mathrm{segmento}$ del catéter, ya que se asocia a bacteriemia relacionada a CVC. Con este punto de corte, los autores encontraron $93 \%$ de sensibilidad y $94 \%$ de especificidad en el diagnóstico de bacteriemia relacionada a CVC. Recupera microorganismos de la superficie interna y externa del dispositivo, y a diferencia del cultivo semicuantitativo del extremo distal, permite cuantificar recuentos altos de bacterias. Kelly et a ${ }^{12}$ confirmaron que un recuento $<10^{3}$ ufc no se correlaciona con bacteriemia relacionada a CVC. Sherertz et $\mathrm{al}^{13}$ en un estudio comparativo de la sonicación versus el método semicuantitativo, mostraron que la sonicación de ambos segmentos del catéter (su extremo distal y el trayecto) es significativamente más sensible que el cultivo semicuantitativo del extremo distal para el diagnóstico de bacteriemia relacionada a CVC.

Cultivo semicuantitativo. Método descrito por Maki et al en $1977^{3}$, considerado el método de referencia para el diagnóstico de infección relacionada a CVC. Consiste en hacer rodar un segmento del catéter ( $5 \mathrm{~cm}$ del extremo distal) en una placa de agar sangre 4 veces hacia adelante y atrás y se incuba durante 24 horas a $37^{\circ} \mathrm{C}$. Se acepta como criterio de colonización significativa la presencia de 15 o más ufc por placa. La sensibilidad del método encontrada por los autores en 5 episodios de bacteriemia relacionada a catéter fue de $100 \%$, con una especificidad de $75 \%$. Se demostró que con este punto de corte el valor predictivo de bacteriemia relacionada a catéter era de $16 \%$. Sólo recupera los microorganismos de la superficie externa del catéter, por lo que su máxima utilidad es en catéteres de corta duración con menos de 10 días de permanencia, ya que en esta etapa predomina la colonización a través de la piel del sitio de inserción y la migración posterior al extremo distal por la superficie externa del catéter. Moyer et al ${ }^{14}$ también describieron $100 \%$ de sensibilidad en el diagnóstico de bacteriemia relacionada a CVC.

En un meta-análisis realizado por SiegmanIgra et $\mathrm{al}^{7}$ se demostró que los métodos cuantitativos son mejores que los semicuantitativos en el diagnóstico de bacteriemia relacionada a CVC, ya que presentan una sensibilidad global de $94 \%$ y una especificidad global de $92 \%$, en comparación con $85 \%$ global de sensibilidad y especificidad para los métodos semicuantitativos. Los mismos autores demostraron en un análisis a través de curvas ROC (receiver operating characteristic), para comparar la exactitud y precisión de un método, que el método de diagnóstico que presenta mayor área bajo la curva es el método cuantitativo por sonicación (mejor sensibilidad y especificidad combinada).

\section{Tinción del catéter}

- Tinción de Gram del extremo distal: descrito por Cooper et $\mathrm{al}^{15}$, consiste en la tinción de un segmento del catéter y observación con lente de inmersión. Requiere una observación mínima durante 3 a 10 minutos para visualizar los microorganismos de la superficie externa del 
catéter. Se considera positivo si se observa 1 microorganismo cada 20 campos. Utilizando como estándar la colonización significativa por el método semicuantitativo, presenta una sensibilidad de $100 \%$, especificidad de $96 \%$, valor predictivo positivo de $83,9 \%$ y valor predictivo negativo de $100 \%$ para el diagnóstico de colonización del catéter. El valor predictivo positivo para bacteriemia relacionada a CVC fue de $34 \%$. Su principal utilidad sería si la tinción de Gram no detecta microorganismos, ya que prácticamente descartaría colonización significativa del CVC. Collignon et al ${ }^{16}$ reportaron una sensibilidad de $83 \%$ y una especificidad de $81 \%$ para el diagnóstico de colonización de la superficie externa, utilizando como referencia el cultivo semicuantitativo del extremo distal. El valor predictivo positivo para el diagnóstico de bacteriemia relacionada a CVC fue de $8 \%$.

- Tinción con anaranjado de acridina del extremo distal: Descrito por Zufferey et $\mathrm{al}^{17}$. Es un método similar a la tinción de Gram pero por ser una tinción fluorescente, permite una observación con un aumento menor, lo que reduce el tiempo de observación. Si se observa fluorescencia, se utiliza inmersión. Se considera positivo la visualización de uno o más microorganismos fluorescentes. Se describe para esta técnica una sensibilidad de $84 \%$ (mejor que con la tinción de Gram) y especificidad de $99 \%$, con un valor predictivo positivo de $99,5 \%$ para el diagnóstico de colonización del catéter, los que en su mayoría fueron catéteres periféricos.

La limitación de estos métodos tintoriales es que sólo se han estudiado para el diagnóstico de colonización y que no permiten la identificación del microorganismo y su relación con los microorganismos aislados en los hemocultivos. Tampoco permiten la realización de estudios de susceptibilidad.

\section{Métodos de diagnóstico conservadores (sin remoción del catéter)}

El objetivo de estos métodos es evitar el retiro innecesario de catéteres ${ }^{6}$, lo que ocurre en $\sim 75$ a $85 \%$ de los casos. Por otro lado, los catéteres tunelizados y especialmente aquellos con bolsillo subcutáneo requieren de procedimientos quirúrgicos para su retiro, y muchos pacientes inmunocomprometidos no están en condiciones de recibir otro dispositivo en plazo breve, además del costo que estos dispositivos y procedimientos implican.
Se han descrito como herramientas diagnósticas: hemocultivos cuantitativos, cultivos superficiales, citocentrifugación con tinción de naranja de acridina y tiempo diferencial hasta la detección de crecimiento bacteriano entre hemocultivo periférico y central.

Hemocultivo cuantitativo. Consiste en la obtención de una muestra de sangre heparinizada por venopunción y, simultáneamente, una muestra de sangre heparinizada a través del catéter, además de dos hemocultivos periféricos. Las muestras para estudio cuantitativo son sembradas en medios sólidos e incubadas paralelamente de modo de obtener un recuento de colonias expresado en ufc por ml de sangre. Posteriomente, se calcula la razón ufc central/ufc periférica. Una relación catéter/sangre periférica $\geq 4: 1$ en el recuento de colonias es considerada indicativa de infección asociada al catéter. No hay acuerdo en el número de lúmenes a estudiar: algunos expertos recomiendan que las muestras sean obtenidas de cada lumen en aquellos catéteres multilumen, en cambio otros recomiendan la obtención de una sola muestra a través del lumen utilizado para la nutrición parenteral total.

La sensibilidad de este método varía de 79 a más de $80 \%$ y su especificidad de 94 a $100 \%$. Su desventaja es la complejidad técnica, necesita la existencia de bacteriemia y que la sangre refluya fácilmente del lumen del catéter. Considerando un punto de corte de 4:1 (central versus periférico) la sensibilidad observada ha sido de $94 \%$ y la especificidad de $100 \%$. Considerando un recuento central > $100 \mathrm{ufc} / \mathrm{ml}$ con hemocultivo periférico negativo, la sensibilidad descrita ha sido de $82 \%$ y la especificidad de $100 \%$.

$\mathrm{Al}$ menos tres estudios recientes han demostrado la utilidad de este método. Estos estudios han sido bien diseñados, prospectivos, de cohorte $\mathrm{y}$ con un gold standard establecido.

Fan et $\mathrm{al}^{18}$, compararon los hemocultivos cuantitativos con el método semicuantitativo de Maki en 24 pacientes sometidos a alimentación parenteral. Con un punto de corte de $7 / 1$ en la razón central/periférico obtuvieron una sensibilidad de $77,8 \%$ y una especificidad de $100 \%$ para bacteriemia relacionada a catéter.

Capdevila et $\mathrm{al}^{19}$ estudiaron lo mismo pero en 107 CVCs de pacientes de medicina, cirugía y cuidados intensivos. Con un punto de corte más bajo, de $4 / 1$, obtuvieron una sensibilidad de $94 \%$ y una especificidad de $100 \%$ al comparar con el método semicuantitativo.

Por último, Quillici et $\mathrm{al}^{20}$, estudiaron 283 CVCs en pacientes de cuidados intensivos y usando como gold standard la técnica cuantitativa de 
Cleri-Brun-Buisson, con un punto de corte de $8 / 1$ obtenido mediante curva ROC, encontraron una sensibilidad de $92,8 \%$ y una especificidad de $100 \%$ para bacteriemia relacionada a catéter. Se han descrito tres alternativas metodológicas para esta técnica:

- Obtenga $2 \mathrm{ml}$ de sangre por punción periférica y $2 \mathrm{ml}$ de sangre por el catéter en jeringa heparinizada, con tapa estéril. Agregue $1 \mathrm{ml} \mathrm{de}$ sangre sin diluir y $1 \mathrm{ml}$ de sangre en diluciones de 1/10,1/100 y 1/1.000 con caldo infusión cerebro-corazón (BHI) a $19 \mathrm{ml}$ de agar BHI enfriado a $45^{\circ} \mathrm{C}$ y vierta a placas de Petri. Incube a $37^{\circ} \mathrm{C}$ y observe desarrollo bacteriano diariamente durante tres días. Compare el crecimiento de la o las placas centrales con la placa periférica y establezca la razón ufc central/ufc periférica.

- Método propuesto por Raucher ${ }^{21}$, que consiste en la inoculación de $0,5 \mathrm{ml}$ de sangre en placas de agar chocolate, evitando el uso de diluciones; sin embargo, la sensibilidad del método es menor en comparación al método con diluciones.

- Obtenga $10 \mathrm{ml}$ de sangre por el catéter central y $10 \mathrm{ml}$ de sangre por venopunción en tubos de lisis-centrifugación (ISOLATOR, Wampole). Agite enérgicamente los tubos durante 20 segundos y centrifugue a $3.000 \mathrm{~g}$ en una centrífuga refrigerada. Siembre $0,1 \mathrm{ml}$ del sedimento de cada tubo en una placa de agar sangre. Se considera positivo para bacteriemia asociada a CVC si el recuento del hemocultivo central es 10 veces mayor que el recuento del periférico, o si el recuento central presenta más de $100 \mathrm{ufc} / \mathrm{ml}$ en ausencia de foco primario.

Cultivo superficial. Corresponde al cultivo semicuantitativo de la piel descrito por Bjornson et $\mathrm{al}^{22}$. Consiste en un cultivo de piel de un área de $10 \mathrm{~cm}^{2}$ alrededor del sitio de inserción del CVC con una tórula estéril humedecida, cuidando de no pasar dos veces por el mismo sitio. Posteriormente, los microorganismos son eluídos de la tórula y sembrados en forma cuantitativa. Hubo asociación significativa $(\mathrm{p}<0,005)$ entre la presencia de más de $10^{3}$ ufc/placa en el cultivo superficial y la colonización significativa del extremo distal y el trayecto del CVC.

Cultivo semicuantitativo de la conexión. Descrito por Cercenado et $\mathrm{al}^{23}$, consiste en introducir una tórula de alginato de calcio estéril, rotarla al interior de la conexión y sembrarla en una placa de agar sangre de cordero. Se acepta como criterio de positividad un crecimiento bacteriano mayor o igual de $15 \mathrm{ufc} /$ placa. Los autores encontraron un valor predictivo positivo de $66,2 \%$ y negativo de $96,7 \%$ en el diagnóstico de infección relacionada a CVC, que sólo se refiere como colonización significativa y no bacteriemia relacionada a CVC. Kite et $\mathrm{al}^{24}$, utilizando un método similar con un cepillo endoluminal y sonicando la punta del cepillo en CVCs con 9,5 días de permanencia, encontró que la mejor sensibilidad y especificidad para el diagnóstico de bacteriemia relacionada a CVC se obtenía por este método (95 y 84\%) en comparación con el cultivo semicuantitativo del extremo distal $(82$ y $66 \%)$ y el método de flush $(75$ y $84 \%$ ), respectivamente. Utilizó un punto de corte de $10^{2} \mathrm{ufc} / \mathrm{ml}$. La ventaja de estos métodos es que no requieren el retiro del catéter; sin embargo, sólo cultivan la superficie interna del catéter.

Citocentrifugación con tinción posterior con anaranjado de acridina. Descrita por Kite et $\mathrm{al}^{25}$, consiste en obtener $50 \mu \mathrm{l}$ de sangre por venopunción y por catéter y producir la lisis de los glóbulos rojos mediante la adición de ácido edético. Las muestras se cargan en un tubo de poliestireno y se les agrega 1 a $2 \mathrm{ml}$ de formalina en solución salina durante 2 minutos. La mezcla se centrifuga a $353 \mathrm{~g}$ durante 5 minutos. El sedimento se homogeniza mediante vórtex durante 5 segundos y se transfiere a la cúpula del Cytospin $^{\mathrm{TM}}$ (Shandon, Runcorn, UK). La citocentrifugación a $153 \mathrm{~g}$ durante 5 minutos permite la formación de una monocapa celular sobre un portaobjetos; luego se utiliza anaranjado de acridina que tiñe el ADN bacteriano. El método evaluado en 50 episodios de bacteriemia relacionada a CVC mostró una sensibilidad de $96 \%$ y especificidad de $92 \%$, utilizando como gold standard de bacteriemia la presencia de hemocultivos cuantitativos periféricos por lisis-centrifugación más un cultivo del extremo distal del catéter positivo al mismo microorganismo. Es la única referencia en la literatura médica que ha utilizado este método, que es laborioso y requiere equipamiento de alto costo (citocentrífuga y microscopia de fluorescencia).

Tiempo diferencial de los hemocultivos. Es un método relativamente nuevo. Descrito inicialmente por Blot et $\mathrm{a}^{26}$, compara el tiempo diferencial de positividad de hemocultivos cualitativos de sangre obtenida a través del catéter y por venopunción, utilizando sistemas de hemocultivos automatizados. Se ha señalado como indicativo de bacteriemia relacionada a CVC un tiempo diferencial (valor de corte) de 120 minutos a favor del hemocultivo central con respecto del periférico. El fundamento de este método es que a mayor carga bacteriana, menor es el tiempo nece- 
sario para que un hemocultivo sea positivo en un sistema automatizado con monitorización continua. La validación de esta relación con estudios in vitro ha sido concluyente según Rogers et $\mathrm{al}^{27}$. Este método tiene una sensibilidad de $94 \%$ y especificidad de $91 \%$ para el diagnóstico de bacteriemia relacionada a CVC en catéteres de larga duración en centros oncológicos ${ }^{28,29}$. Un trabajo reciente realizado en pacientes pediátricos oncológicos con catéteres de larga duración mostró una sensibilidad y especificidad de $87,5 \%$ y $100 \%$, respectivamente, empleando un punto de corte de dos horas diferenciales entre los hemocultivos centrales y los periféricos ${ }^{30}$. Este método es factible de realizar sólo en centros que cuenten con sistemas de hemocultivos automatizados. Estudios respecto de su uso en catéteres de corta duración no han sido concluyentes ${ }^{31}$.

\section{Recomendaciones para el diagnóstico de infección relacionada a catéteres vasculares según tipo de paciente y de dispositivo}

Los principales problemas para comparar los diferentes trabajos publicados han sido la diversidad de definiciones del gold standard (especialmente cuando se refiere a bacteriemia relacionada a CVC) y el tiempo de permanencia de los catéteres in situ. Frecuentemente se han comparado resultados de métodos de diagnóstico en estudios realizados en CVCs de corta duración versus CVCs de larga duración, siendo conocido que la duración de la cateterización es un factor preponderante en el tipo de colonización (endoluminal o de la superficie externa). Estudios realizados en catéteres de pacientes oncológicos de larga duración no son extrapolables a catéteres de corta duración o vice versa.

Las siguientes recomendaciones se han basado en la evidencia disponible en la literatura médica y son aplicables para cualquier tipo de catéter.

- Los catéteres venosos centrales, independientemente de su tipo o localización, no deben ser cultivados rutinariamente. Es una práctica de alto costo, que sobrecarga de trabajo al laboratorio y la demostración microbiológica de colonización no se correlaciona con el cuadro clínico de bacteriemia relacionada a $\mathrm{CVCs}^{7,32}$. Recomendación tipo A.

- Se recomienda la elección de métodos que no requieren el retiro del catéter versus aquellos métodos de diagnóstico con remoción del CVC. Sin embargo, los métodos mejor validados en la literatura médica (Categoría A) son métodos no conservadores.

\section{Métodos de diagnóstico no conservadores (requieren el retiro del catéter)}

Cultivo cualitativo. Dada su baja especificidad, no se recomienda este método para el diagnóstico microbiológico de la infección relacionada a CVC. Calidad de la evidencia y fuerza de la recomendación: E.

Cultivo cuantitativo (métodos del flush, cuantitativo simplificado o sonicación). Hay evidencia en la literatura que los métodos cuantitativos son superiores a otras técnicas de diagnóstico. Los métodos cuantitativos tienen la ventaja además de recuperar microorganismos de la superficie interna y externa del catéter que se liberan desde la capa de biofilm. El método del irrigación o flush sólo recupera los microorganismos intraluminales. Estas técnicas tienen mejor rendimiento en catéteres de larga duración, debido a que a partir del séptimo día empieza a predominar la colonización intraluminal del catéter. Son métodos recomendados además para aquellos laboratorios de microbiología que cuenten con un equipamiento adecuado (vórtex, sonicador) y personal entrenado en estos métodos. Entre las desventajas se cita el equipamiento adicional requerido y la difícil estandarización del ultrasonido. Calidad de la evidencia y fuerza de la recomendación: A.

Cultivo semicuantitativo. Continúa siendo el método más utilizado. No requiere gran equipamiento y es de bajo costo. Sólo recupera microorganismos desde la superficie externa del catéter, por lo que su máxima utilidad es para el diagnóstico de bacteriemia relacionada a catéteres de corta duración. Calidad de la evidencia y fuerza de la recomendación: A.

Tinción del catéter. Hay evidencia en la literatura para sensibilidad y especificidad de esta técnica respecto a colonización y no a bacteriemias relacionadas a catéteres, lo que puede conducir a sobrediagnóstico y sobretratamiento por colonización y no bacteriemia. No se recomienda su uso. Calidad de la evidencia y fuerza de la recomendación: D.

\section{Métodos conservadores (no requieren el retiro del catéter)}

Hemocultivo cuantitativo pareado. Este método se ha recomendado tradicionalmente para infecciones asociadas a dispositivos implantables de larga duración o cuando las condiciones del paciente no permiten su extracción (neonatos, pacientes con coagulopatías, nulo acceso vascular: grandes quemados, obesos mórbidos). Se recomienda como punto de corte mínimo la relación 4:1 del hemocultivo central respecto del periférico; 
esto significa que el laboratorio debe informar todos los recuentos $\geq$ de $4: 1$, con lo que mejora la especificidad. También se debe considerar significativo un recuento central > $100 \mathrm{ufc} / \mathrm{ml}$. Calidad de la evidencia y fuerza de la recomendación para catéteres de larga duración: A.

Tiempo diferencial de positividad de hemocultivos. Para catéteres de larga duración ha mostrado ser de gran utilidad y bajo costo. Se requieren más estudios prospectivos que permitan validar esta técnica para su uso rutinario en catéteres de corta duración ya que, al igual que los hemocultivos cuantitativos, sólo recuperan los microorganismos presentes en el lumen del catéter. Calidad de la evidencia y fuerza de la recomendación para catéteres de larga duración: A (recomendado). Calidad de la evidencia y fuerza de la recomendación para catéteres de corta duración: B.

Cultivos semicuantitativos de la conexión. Sólo dos publicaciones en la literatura avalan su uso. Tendría especial utilidad en colonizaciones endoluminales y cuando los resultados son negativos, ya que presenta una buena especificidad. $\mathrm{Su}$ uso rutinario no se recomienda. Calidad de la evidencia y fuerza de la recomendación: C.

Citocentrifugación y tinción con anaranjado de acridina. Es un método promisorio, pero necesita más estudios para ser validado. Es engorroso y requiere equipamiento de alto costo. Por ahora su uso no se recomienda. Calidad de la evidencia y fuerza de la recomendación: C.

Recomendaciones respecto de los métodos de diagnóstico. De acuerdo a la evidencia expuesta anteriormente es necesario elaborar las recomendaciones según el tiempo que el catéter esté instalado:

- En el caso que el catéter deba ser retirado y se disponga de su extremo distal, se recomienda realizar alguna técnica cuantitativa de este extremo, especialmente la técnica de sonicación o la del método cuantitativo simplificado (flush + vórtex), ya que estos métodos permiten la recuperación de microorganismos intraluminales y de la superficie externa, por lo que puede ser utilizados en catéteres de corta y larga duración.

- Si los laboratorios no disponen de los insumos necesarios (sonicador para el primer método y vórtex para el segundo), entonces el método semicuantitativo de Maki puede ser utilizado pero, dado que sólo recupera microorganismos de la superficie externa, debe ser utilizado en catéteres de corta duración.

- El cultivo del extremo distal debe acompañarse al menos de 1 hemocultivo obtenido por venopunción. La obtención de 2 hemocultivos periféricos a partir de diferente sitio de punción mejora la especificidad, ya que disminuye la probabilidad que el hemocultivo positivo en caso de Staphylococcus coagulasa negativo sea interpretado como una contaminación al momento de la obtención de la muestra.

- En el caso de catéteres con más de un lumen, se recomienda la obtención al menos, de las muestras por el lumen de la nutrición parenteral total o el lumen distal.

- En el caso que el catéter no pueda ser retirado, se deben elegir métodos conservadores. La recomendación es en primera instancia efectuar hemocultivos cuantitativos pareados con las técnicas descritas y validadas en la literatura. Si por la complejidad de estos métodos no es posible la realización de los hemocultivos cuantitativos, entonces se recomienda el tiempo diferencial de la positividad de los hemocultivos, en aquellos laboratorios que dispongan de sistemas automatizados.

\section{Recomendaciones para catéteres de hemodiálisis}

No existen estudios que describan la sensibilidad y especificidad de los distintos métodos para el diagnóstico de las infecciones asociadas a catéteres de hemodiálisis. En muchos estudios se han usado diferentes definiciones, principalmente operacionales, basadas en la necesidad de retiro del catéter o intensidad del tratamiento necesario, más que en base a la patogenia de la infección o los hechos de laboratorio que establecen el diagnóstico. De esta forma, la infección del catéter de hemodiálisis ha sido vista hasta ahora a la luz de los conocimientos obtenidos de estudios en CVCs utilizados para otros fines y las estrategias diagnósticas se han extrapolado y adaptado sin haber sido validadas ${ }^{33-39}$.

Las guías clínicas más aceptadas en la actualidad, Dialysis Outcome Quality Initiative (DOQI), desarrolladas por la National Kidney Foundation establecen categorías diagnósticas y el tratamiento para diferentes tipos de infecciones relacionadas al catéter de hemodiálisis, pero no establecen un método diagnóstico preferido basado en la evidencia $^{40}$.

\section{Recomendaciones para catéteres venosos centrales periféricamente instalados (CCPI)}

No hay recomendaciones en la literatura sobre métodos de diagnóstico diferentes que para CVCs 
transitorios o permanentes. No hay datos en la literatura para suponer que los resultados de estos estudios sean extrapolables a los catéteres tipo $\mathrm{CCPI}^{41-43}$.

\section{Bibliografía}

1.- Dittmer I D, Shap D Mc Nulty C A, Williams A J, Banks R A. A prospective study of central venous hemodialysis catheter colonization and peripheral bacteremia. Clin Nephrol 1999; 51: 34-9.

2.- Raad I, Costerton W, Sabharwal U, Sacilowski M, Anaissie E, Bodey G. Ultraestructural analysis of indwelling vascular catheters: a quantitative relationship between luminal colonization and duration of placement. J Infect Dis 1993; 168: 400-7.

3.- Maki D G, Weise C E, Sarafin H W. A semiquantitative culture method for identifying intravenous-catheterrelated infection. N Engl J Med 1977; 296: 1305-9.

4.- Liñares J, Sitges-Serra A, Garau J, Pérez J L, Martín R. Pathogenesis of catheter sepsis: a prospective study with quantitative and semicuantitative cultures of catheter hub and segments. J Clin Microbiol 1985; 21 : 357-60.

5.- Mermel L A, Farr B M, Sherertz R J et al. Guidelines for the management of intravascular catheter-related infections. Clin Infect Dis 2001; 32: 1249-72.

6.- Ryan J A, Abel R M, Abbott W M, Hopkins T M, Chesney T M. Catheter complications in total parenteral nutrition: a prospective study of 200 consecutive patients. N Engl J Med 1974; 290: 757-61.

7.- Siegman-Igra Y, Anglin A M, Shapiro D E, Adal K A, Strain B A, Farr B M. Diagnosis of vascular catheterrelated bloodstream infection:a meta-analysis. J Clin Microbiol 1997; 35: 928-36.

8.- Cleri D J, Corrado M L, Seligman S J. Quantitative culture of intravenous catheter and other intravascular insert. J Infect Dis 1980; 141: 781-6.

9.- Rello J, Coll P, Ptars G. Laboratory diagnosis of catheter-related bacteremia. Scand J Infect Dis 1991; 23: $583-8$.

10.- Brun-Buisson C, Abrouk F, Legrand P, Huet Y, Larabi S, Rapin M. Diagnosis of central venous catheterrelated sepsis: critical level of quantitative tip cultures. Arch Intern Med 1987; 147: 873-7.

11.- Sherertz R J, Raad I I, Belani A et al. Three-year experience with sonicated vascular catheter cultures in a clinical microbiology laboratory. J Clin Microbiol 1990; 28: 76-82.

12.- Kelly M, Wunderlich L R, McConico S, Peterson L R. Sonicated vascular catheter tip cultures. Quantitative association with catheter-related sepsis and the nonutility of an adyuvant cytocentrifuge Gram stain. Am J Clin Pathol 1996; 105: 210-5.

13.- Sherertz R J, Heard S O, Raad II. Diagnosis of triplelumen catheter infection: comparison of roll plate, sonication, and flushing methodologies. J Clin Microbiolol 1997; 35: 641-6.

14.- Moyer M A, Edwards L D, Farley L. Comparative culture methods on 101 intravenous catheters: Routine, semiquantitative, and blood cultures. Arch Intern Med 1983; 143: 66-9.

15.- Cooper G L, Hopkins C C. Rapid diagnosis of intravascular catheter-associated infection by direct Gram staining of catheter segments. N Engl J Med 1985; 312: 1142-7.
16.- Collignon P, Chan R, Munro R. Rapid diagnosis of intravascular catheter-related sepsis. Arch Intern Med 1987; 147: 1609-12 .

17.- Zuffery J, Rime B, Francioli P, Bille J. Simple method for rapid diagnosis of catheter-associated infection by direct acridine orange staining of catheter tips. J Clin Microbiol 1988; 26: 175-7.

18.- Fan S T, Teho-Chan C H, Lau K F. Evaluation of central venous catheter sepsis by differential quantitative blood culture. Eur J Microbiol Infect Dis 1989; 8: 142-4.

19.- Capdevila J A, Planes A M, Palomar M et al. Value of differential quantitative blood cultures in the diagnosis of catheter-related sepsis. Eur J Clin Microbiol Infect Dis 1992; 11: 403-7.

20.- Quillici N, Audibert G, Conroy M C et al. Differential quantitative blood cultures in the diagnosis of catheterrelated sepsis in intensive care units. Clin Infect Dis 1997; 25: 1066-70.

21.- Raucher H, Hyatt A, Barzilai A et al. Quantitative blood cultures in the evaluation of septicemia in children with Broviac catheters. J Pediatr 1984; 104: 29-33.

22.- Bjornson H S, Colley R, Bower R H, Duty V P, Schwartz-Fulton J T, Fischer J E. Association between microorganism growth at the catheter insertion site and colonization of the catheter in patients receiving total parenteral nutrition. Surgery 1982; 92: 720-7.

23.- Cercenado E, Ena J, Rodríguez-Créixems M, Romero Y, Bouza E. A conservative procedure for the diagnosis of catheter-related infections. Arch Intern Med 1990; 150: 1417-20.

24.- Kite P, Dobbins M H, Wilcox M H et al. Evaluation of a novel endoluminal flush method for in situ diagnosis of catheter related sepsis. J Clin Pathol 1997; 50: $278-82$.

25.- Kite P, Dobbins B M, Wilcox M H, McMahon M J. Rapid diagnosis of central -venous-catheter-related bloodstream infection without catheter removal. Lancet 1999; 354: 1504-7.

26.- Blot F, Schmidt E, Nitenberg G et al. Earlier positivity of central-venous-versus peripherical-blood cultures is highly predictive of catheter-related sepsis. J Clin Microbiol 1998; 36: 105-9.

27.- Rogers M S, Oppenheim B A. The use of continuous monitoring blood culture systems in the diagnosis of catheter related sepsis. J Clin Pathol 1998; 51: 635-7

28.- Blot F, Nitenberg G, Chachaty E et al. Diagnosis of catheter-related bacteraemia: a prospective comparision of the time to positivity of hub-blood versus peripheral-blood cultures. Lancet 1999; 354: 1071-6.

29.- Malgrange V B, Escande M C, Theobald S. Validity of earlier positivity of central venous blood cultures in comparison with peripheral blood cultures for diagnosing catheter-related bacteremia in cancer patients. J Clin Microbiol 2001; 39: 274-8.

30.- Gaur A H, Flynn P M. Differential time to positivity (DTP): A simple method for the diagnosis of catheterrelated infection (CRI) in immunocompromised pediatrics patients. Abstract \# 624. 40 ${ }^{\text {th }}$ Annual Meeting IDSA. Chicago. October, 2002.

31.- Rijners B J, Verwaest C, Peetersmans W E et al. Difference in time to positivity of hub-blood versus non hub-blood cultures is not useful for the diagnosis of catheter-related bloodstream infection in critically ill patients. Crit Care Med 2001; 29: 1399-403.

32.- Widmer A F, Nettlemen M, Flint K, Wenzel R. The clinical impact of culturing central venous catheters. 
A prospective study. Arch Intern Med 1992; 152: 1299-302.

33.- Nassar G M, Ayus J C. Infectious complications of the hemodialysis access. Kidney Int 2001; 60: 1-13.

34.- Schwab S J, Beathard G. The hemodialysis catheter conundrum: hate living with them, but can't live without them. Kidney Int. 1999; 56: 1-17.

35.- Saad T F. Bacteremia associated with tunneled, cuffed hemodialysis catheter. Am J Kidney Dis 1999; 34: 1114-24.

36.- Butterly D W, Schwab S J. Catheter access for hemodialysis: an overview. Semin Dial 2001; 14 (6): 411-5.

37.- Saad T F. Central venous dialysis catheter: catheter associated infection. Semin Dial 2001; 14 (6): 446-51.

38.- Canaud B. Haemodialsis catheter-related infection: time for action. Nephrol Dial Transplant 1999; 14: 2288-90.

39.- Kovalik E C, Schwab S J. Treatment approaches for infected hemodialysis vascular catheters. Curr Opin Nephrol Hypertens 2002; 11: 593-6.

40.- NKF-K/DOQI Clinical Practice Guidelines for Vascular Access: Update 2000 Am J Kidney Dis 2001; 37: S137-S181.

41.- Gal Egansansivero. ¿Por qué escoger un catéter central periférico? Nursing 1996; 17-23.

42.- Pérez M E. Uso de catéter central insertado periféricamente por vía percutánea en recién nacidos. Pediatría al Día 2000; 18: 27-31.

43.- Ravi R T, Mrci M. Survey of the use of peripherally inserted central venous catheter in children. Pediatrics 1997; 99: 1-4.

Correspondencia a:

Patricia García Cañete

E-mail: pgarcia@med.puc.cl 